\title{
The role of tensins in malignant neoplasms
}

Marcin Nizioł, Anna Pryczynicz

Department of General Pathomorphology, Medical University of Bialystok, Bialystok, Poland

Submitted: 17 August 2020

Accepted: 1 September 2020

Arch Med Sci

DOI: https://doi.org/10.5114/aoms/127085

Copyright $\odot 2021$ Termedia \& Banach

\section{Abstract}

Tensins belong to the family of adhesion proteins which form focal adhesions serving as a bridge between the extracellular matrix and intracellular actin skeleton. The tensin family consists of four members (tensin-1 to -4 ) which are widely expressed in normal and cancerous tissues. The presence of Src homology 2 and phosphotyrosine binding domains is a unique feature of tensins which enables them to interact with tyrosine-phosphorylated proteins in PI3K/AKt and $\beta$-integrin/FAK signaling pathways. The tensin-mediated signaling pathway regulates physiological processes including cell motility and cytoskeleton integrity. The expression of tensins varies among cancers. Several papers report tensins as tumor suppressive proteins, whereas tensins may promote epithelial to mesenchymal transition and cancer cell metastasis. Recent findings and further research on tensins as therapeutic targets in cancers may contribute to identifying effective anti-cancer therapy. In this review we focus on the role of tensins in normal and cancer cells. We discuss potential mechanism(s) involved in carcinogenesis.

Key words: carcinogenesis, adhesion proteins, cancers, tensins.

\section{Introduction}

The communication among cells and adjacent extracellular matrix (ECM) relies on adhesion bonds which are crucial for cell differentiation, morphological architecture and physiological growth. To maintain proper interactions in the cell-cell and cell-matrix junctions, cell adhesion molecules (CAMs) are required. The group of CAMs consists of numerous proteins including major families of integrins, cadherins, selectins, immunoglobulin superfamily and CD44 [1]. They not only maintain cellular integrity, but also transduce signaling, allowing cells to behave normally. Thereby, CAMs play a role in many cellular processes such as inflammation, wound healing, and in terms of carcinogenesis, migration, invasion and metastasis [2]. Cancer cells exhibit impaired morphology as a result of accumulated genetic abnormities, leading to a weakening of cell adhesion and promoting cell spreading [1]. In recent years, CAM-related research has been focused on tensins, which are a family of four adhesion proteins: tensin-1, $-2,-3$ and -4 . They were discovered in the 1990s. For the first time, CDNA (complementary DNA) tensins were isolated by Davis et al. in chicken tissues [3]. These proteins form bridges between actin filaments and $\beta$-integrins - called focal adhesions (FAs) - enabling them to participate in signal transmission between the intracellular environment and the ECM. Tensins are responsible for maintaining the cellular cytoskeleton structure and participate in numerous signaling pathways [4].

\author{
Corresponding author: \\ Marcin Nizioł MSc \\ Department of General \\ Pathomorphology \\ Medical University \\ of Bialystok \\ 13 Waszyngtona St \\ 15-269 Białystok, Poland \\ E-mail: \\ marcin.niziol@umb.edu.pl
}


Moreover, they are engaged in the regulation of cellular migration, proliferation and apoptosis. Tensins are commonly found in many mammalian as well as bird tissues $[3,5,6]$. Currently, their role is being extensively explored in terms of carcinogenesis. Their role in cancers has not been clarified: expression of tensins varies depending on cancer type. So far, it is known that tensins interact with focal adhesion kinase (FAK), p130Cas and phosphoinositide 3-kinase (PI3K) [7] as well regulating Rho GTPase [7], epidermal growth factor receptor (EGFR) and c-Met signaling pathways [4]. All aforementioned findings suggest that tensins participate in cancer development, but little is known about their exact role. In this review, we gather the current knowledge about tensins in the context of their biological and clinical relevance.

\section{Structure and occurrence of tensins}

The proteins of the tensin family are encoded by human genes located on different chromosomes. TNS1 gene that encodes tensin-1 is situated on the long arm of chromosome 2 (2q35); tensin-2 is encoded by the TNS2 gene located on the long arm of chromosome 12 (12q13.13); tensin-3 is encoded by the TNS3 gene located on the short arm of chromosome 7 (7p12.3); and the TNS4 gene encoding tensin- 4 is located on the long arm of chromosome 17 (17q21.2). In the structure of tensin family proteins there are two domains - Src homology 2 ( $\mathrm{SH} 2)$ and phosphotyrosine binding (PTB) - based on which all the four tensins were included in this group of proteins. Both domains have the ability to interact with phosphorylated tyrosine residues $[3,8]$. For example, the $\mathrm{SH} 2$ do- main may bind with phosphorylated tyrosine residues of PI3K and FAK as well as p130Cas, while PTB may also bind with non-phosphorylated tyrosine residues. Additionally, the PTB domain is a place of binding with the NPXY motif in the integrin tail of types $\beta 1,3,5$ and 7 [5].

Tensins $1-3$ also have an $N$-terminal region of the actin-binding domain (ABD), which binds actin filaments. In $\mathrm{C}$ - and $\mathrm{N}$-terminal regions there are 2 sequences that enable focal adhesion binding $(\mathrm{FAB})$. It has been proven that the presence of both these regions is essential for the biological functions of tensins, which are the effect of the phosphorylation of tyrosine, serine or threonine. Increased phosphorylation of these amino acids occurs upon stimulation with growth factors (e.g. platelet-derived growth factor - PDGF), thrombin or angiotensin [5]. On the other hand, tensin-4 is shorter in its structure and does not contain ABD, which differentiates this protein from other tensins. Figure 1 presents the general structure of tensins, and highlights binding sites for specific proteins. Tensins 1-3 also contain the domains of phosphatase (PTPase) and C2 that show homology to PTEN tumor suppressor protein. Additionally, if the PTPase domain is catalytically active, these proteins may demonstrate enzymatic activity [5].

\section{Functions and mechanism of action of tensins}

The biological significance of tensins is reflected by interactions with $\beta$-integrin receptors on cell surfaces and intracellular actin fibers bridging the ECM and the cytoskeleton. Tensins are proteins associated with FAs, which means they play an important role as regulators of cell adhesion and
FAB-N

Focal adhesion binding site
FAB-C

Focal adhesion binding site

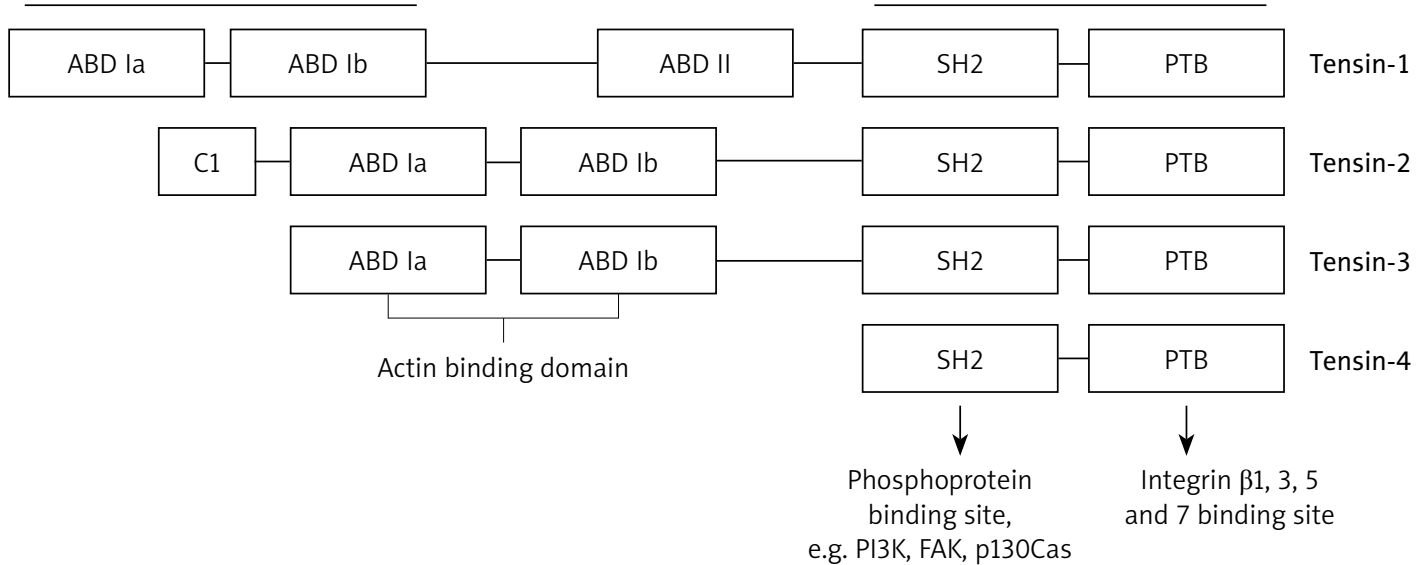

Figure 1. Schematic model displaying general structure of tensins and binding sites to specific molecules such as PI3K, FAK, p130Cas, actin and integrins. ABD - actin binding domain, FAB - focal adhesion binding, PTB - phosphotyrosine-binding domain, $\mathrm{SH} 2$ - Src homology 2 domain, FAK - focal adhesion kinase, PI3K - phosphoinositide 3-kinase 


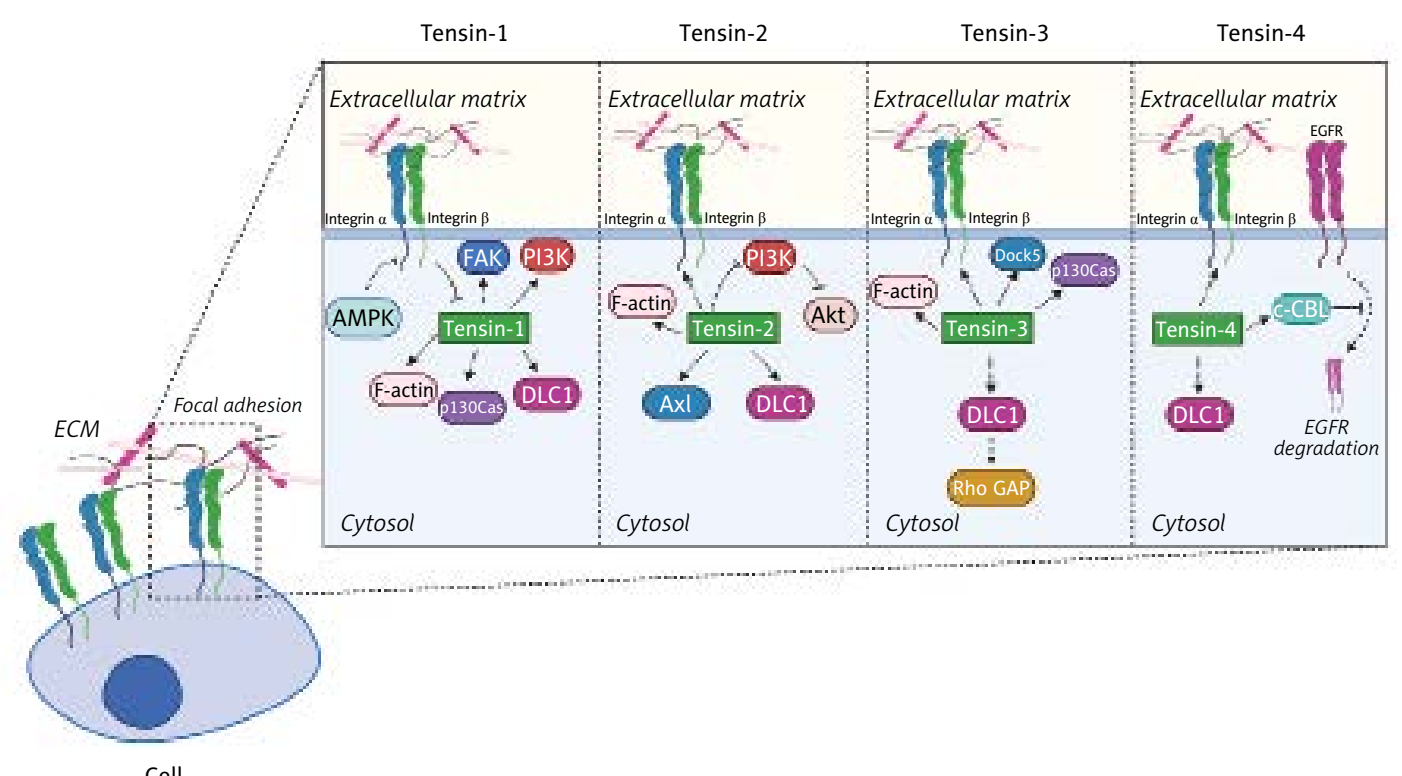

Cell

Figure 2. The biological significance of tensins in cellular functions. Tensins are focal adhesion-related proteins affecting cell migration and adhesion. Tensins 1-3 interact with actin fibers while all four members of the tensin family bind to $\beta$-integrins and DLC1. Tensin-1 regulates FAK, PI3K and p130Cas signaling pathways and it is indirectly inhibited by AMPK. Tensin-2 is a negative regulator of the PI3K/Akt pathway and can bind to Axl. Association of tensin-3 with DLC1 results in Rho GAP activation. In addition, tensin-3 interacts with Dock5 acting as an adaptive molecule. Tensin-4 binding to c-Cbl contributes to suppression of EGFR degradation in lysosomes. FAK - focal adhesion kinase, PI3K - phosphoinositide 3-kinase, DLC1 - deleted in liver cancer 1, AMPK - AMP-activated protein kinase, EGFR - epidermal growth factor receptor, Rho GAP - GTPase-activating protein

migration. Tensins are able to bind pathway signaling molecules due to the presence of various domains in their structure. For example, the PTB domain binds $\beta 1$-integrin, while the $\mathrm{SH} 2$ domain was found to bind PI3K $[9,10]$, FAK and p130Cas [11]. As a result of the association of tensins with these molecules, migration of cells is promoted. At focal adhesion, tensin-1 can link to phosphorylated 130Cas, stimulating the actin cytoskeleton [11]. It is also known that upon stimulation of EGFR, tensin-3 regulates cell migration via dissociation of FAK and p130Cas from the complex consisting of tensin-3FAK-p130Cas. This finding suggests that tensin-3 is an EGFR-downstream protein mediating cellular signaling pathways [10]. Interaction of tensin-4 with PI3K leads to activation of the Akt-mediated signaling pathway, which is involved in epithelial to mesenchymal transition (EMT) [12]. It has been found that accelerated cell proliferation and migration may be related to enhanced expression of tensin-4 correlated with activated PI3 and Akt kinases [13]. Apart from the ability of binding to integrins, tensins were found to interact with receptor tyrosine kinases (RTKs) and the Rho GAP DLC1 (deleted in liver cancer 1) [14]. Additionally, tensins as FA-associated proteins are also present in podosomes [15] and invadopodia [16], which are crucial in EMT. Formation of these structures enables cells to migrate and contributes to invasion and metastasis of tumor cells [17]. Among tensins, tensin-4 is mainly reported as a molecule participating in EMT through various signaling pathways such as Ras/Raf/extracellular signal-regulated kinase (ERK), TGF- $\beta$, Akt/PI3K, and signal transducer and activator of transcription 3 (STAT3) and growth factors-related pathways [13, 18-21].

\section{Tensins}

The section below covers the current knowledge about tensins and their implications for cell adhesion in detail. Each of the tensins has been carefully described in the context of molecules with which they interact. Figure 2 provides insight into their function in cells and shows how tensins affect intracellular metabolism.

\section{Tensin-1}

Tensin-1 is a protein with a molecular mass of $220 \mathrm{kDa}$, located at focal adhesions and transmembrane connections between the cell cytoskeleton and ECM [22]. Studies evaluating the expression of tensin- 1 in human tissues showed that the level of this protein expression is the highest in the heart, skeletal muscles, kidneys, lungs, small intestine, liver, colon, prostate, testes and ovary [23]. Low or undetectable levels of tensin-1 expression were observed in the brain, thymus and circulating leukocytes [24]. During apoptosis, tensin-1 is a substrate for the active form 
of caspase-3, which indicates that tensin-1 degradation in the final phase of apoptosis is crucial for the complete disturbance of cell integrity [5]. Tensin-1 undergoes the process of degradation triggered by proteolytic activity of calpain II or caspases. Calpain II digests tensin-1 (two fragments: 45 and $40 \mathrm{kDa}$ ) as well as other proteins forming focal adhesions in order to maintain normal cell morphology. It is known that calpain regulates integrin-downstream signaling pathways and cytoskeleton integrity. Cellular morphology changed while tensin degradation was inhibited by calpain inhibitor, suggesting that cell mobility or focal adhesion formation was impaired [23].

Structurally, tensin-1 is composed of three regions involved in protein-protein interactions [5]. It contains the $\mathrm{N}$-terminal region of ABDla/b/ $\mathrm{FAB}-\mathrm{N}$, the central $\mathrm{ABD}$ II region and the $\mathrm{C}$-terminal region consisting of 2 domains: $\mathrm{SH} 2$ and PTB. The N-terminal fragment enables this protein to interact with actin. Moreover, it has been proven that tensin-1 lowers the rate of actin polymerization [24]. The C-terminal fragment of tensin-1 consists of two motifs: SH2 and PTB. It has been demonstrated that the expression of tensin- 1 is stimulated by a number of factors including ECM [25], thrombin [26], oncogenes ( $\mathrm{v}-\mathrm{Src}$ and BCR$A B L)$ [27], PDGF [28] and angiotensin [29]. Another important interaction involving tensin-1 is connected with the activity of small Rho GTPase that regulates focal adhesions and actin fibers. A key role is also played by the tumor suppressor molecules DLC1 and DLC3. C-terminal domain of tensin-1 binds DLC1 and DLC3. It has been observed that in many cancers the expression of these proteins is suppressed, which may depend on the tensin-1-Rho GTPase relationship [29]. Furthermore, the C-terminal PTB domain interacts with the NPXY motif of $\beta$-integrin. Due to the binding to integrins, which are cell membrane proteins, tensin-1 mediates the processes of cell-to-ECM or cell-to-cell adhesion. The binding of tensin- 1 to $\beta$-integrin results in signal transduction and stimulation of this signaling pathway, which promotes the formation of more adhesion sites [14]. It has been demonstrated that $\beta$-integrin inhibitor is a protein kinase activated by AMP (AMPK) that inhibits tensin-1 expression [30]. The silencing of AMPK contributes to increased tensin-1 expression, boosted expression of $\beta$-integrin and creation of adhesions that bind $\beta 1$-integrins, thus supporting their activity and promoting the formation of new adhesions with the surrounding cell structures or ECM [31]. On the other hand, the $\mathrm{SH} 2$ domain may be bound to phosphorylated amino acids (mainly tyrosine residues) of protein kinases, including
PI3K, as well as FAK and p130Cas [7]. Moreover, the $\mathrm{SH} 2$ domains were found to interact with various tyrosine-phosphorylated signaling molecules, including paxillin [32], EGFR, c-Met [4] and $\mathrm{c}-\mathrm{Cbl}$ [33].

It is currently believed that tensin-1 accompanies adhesion structures (e.g. invadopodia, podosomes, primary sited of focal adhesions) in which it participates in the regulation of the cell cytoskeleton by modulating the dynamics of actin fiber and signal transduction pathways dependent on Rho GTPase [7].

\section{Tensin-2}

Tensin-2 was first identified by Chen et al. [22], who provided insight into its gene structure and pattern of expression as well as protein mass and intracellular localization. Hafizi et al. [34] reported tensin-2 as a protein binding to the intracellular region of AxI RTK. The researchers showed that high levels of tensin-2 expression occur in the heart, kidneys, skeletal muscles and liver, which indicates a similar distribution of proteins from the tensin family. They also observed that tensin-2 is located in focal adhesions. Moreover, the same authors conducted studies to determine the location of tensin-2 in cell organelles. They demonstrated frequent co-location of tensin-2 and DLC1 protein in cytoplasmic bodies. Moreover, they detected poor co-location of tensin-2 with phalloidin, typical of F-actin fibers [34]. The binding of tensin-2 to DLC1 occurs via the $\mathrm{SH} 2$ domain, which contributes to cell contractility modulation [35]. In addition, $\mathrm{SH} 2$ domains of tensin- 2 were found to interact with the tyrosine-phosphorylated signaling molecule $\mathrm{Axl}$ [36]. It was also observed that tensin-2 overexpression results in inhibited proliferation and motility of renal cells and increased apoptosis under starvation. Increased expression of tensin-2 was accompanied by doubled activity of effector caspase-3 [37]. Moreover, the level of phosphorylation of serine and threonine residues in Akt kinase was decreased, which resulted in its reduced activity [29]. Hafizi et al. [38] demonstrated that tensin-2 regulates the Akt/ PI3K signaling pathway, affecting processes related to cell proliferation and migration. As a negative regulator of this pathway, the protein acts as a tumor suppressor. In the HEK293 cell line with tensin-2 overexpression, the cells showed reduced ability to migrate. The consequence of increased tensin-2 expression was also reduced proliferation potential of cells compared to the control cells. The molecular mechanisms explaining the above cell processes are: significantly reduced phosphorylation of proteins from the Akt/PI3K pathway as well as reduced enzymatic activity of Akt kinase itself. Literature reports indicate that tensin-2 
serves as a negative regulator of the signal transduction pathway dependent on PI3K/Akt.

\section{Tensin-3}

The structure of tensin-3 is similar to that of tensin- 1 and tensin-2, but excluding the domains ABDIl (which is present in tensin-1) and C1 (present in tensin-2). Tensin-3, similarly to tensin-1 and -2 , interacts with DLC1, although the relationship between these compounds has not been fully understood. In the $N$-terminal domain of DLC1, Tripathi et al. [39] determined 4 phosphorylation sites (S120, 205, 422, 509) that promote tensin-3 binding, which results in stimulation of the Rho GAP signaling pathway. It has been observed that the structure of DLC1 contains the SAM domain. It can also bind to tensin-3 and is an intramolecular inhibitor of Rho GAP activity, as confirmed by the severity of Rho inactivation after silencing this domain in DLC1. Binding to SAM occurs through the $\mathrm{N}$-terminal $\mathrm{ABD}$, which stimulates Rho GAP activity [7]. Touaitahuata et al. [40] found that tensin-3 interacts with Dock 5 in osteoclast podosomes. Tensin-3 probably also acts as an adaptive protein mediating podosome modeling. The authors of this paper developed the theory that tensin-3 is involved in the transformation of podosomes into more complex structures through interaction with p130Cas. The hypothesis assumes that this process is regulated by Dock5.

\section{Tensin-4}

Tensin-4, known as C-terminal tensin-like molecule, is a protein of the tensin family with the lowest molecular weight. It is a consequence of the presence of only 2 domains, SH2 and PTB, at the carboxyl-terminal [5]. This protein was classified as a member of the tensin family due to the presence of the said domains, almost identical genomic structures encoding them as well as location in focal adhesion sites [41]. This protein occurs in a few tissues, mainly in the prostate [42]. A number of growth factors have been observed to stimulate tensin-4 expression, including epidermal growth factor (EGF), transforming growth factor $\beta$ (TGF- $\beta$ ) and insulin-like growth factor 1 (IGF-1). Tensin-4 is stimulated mainly through the following signaling pathways: Ras/ Raf/ERK, PI3K/Akt, STAT and phospholipase C (PLC) [21].

Biological functions associated with the expression of tensin-4 include processes involved in cellular motility, apoptosis, homeostasis of growth factors and oncogenic potential $[18,43]$. Tensin-4 overexpression contributes to the migration of cells by binding the PTB domain to the $\beta 1$-integrin tail, stimulating integrin-related kinase expres- sion (ILK) or interacting with DLC1 tumor suppressor [41]. In normal cells, tensin-4 is degraded by proteolytic cut by caspase-3 during staurosporine-induced apoptosis. The remaining PTB domain may limit excessive cell growth by inducing apoptosis [41].

Hong et al. [33] investigated the role of tensin-4 in EGFR-induced signaling, suggesting that tensin-4 can diminish degradation of EGFR. It is well known that the EGFR signaling pathway plays a crucial role in cell proliferation, migration, and differentiation [44]. The SH2 domain of tensin-4 binds to $\mathrm{c}-\mathrm{Cbl}$, which also regulates EGFR degradation through interaction of ubiquitin with activated EGFR [45]. Then, ubiquitin-conjugated EGFR is internalized and degraded in lysosomes [46]. EGFR overexpression leads to promotion of excessive cell proliferation and tumor formation; thus EGFR regulation needs to be tightly controlled. Hong et al. [33] revealed that tensin-4 via binding to $\mathrm{c}$ - $\mathrm{Cbl}$ contributes to suppression of EGFR degradation. Tensin-4 has been found to be overexpressed in many cancers, which means that the tensin-4-dependent mechanism of EGFR degradation may serve as a potential target in cancer treatment.

The strength of cell-cell adhesion is very often weakened under the epidermal growth factor (EGF) condition, leading to enhanced cell migration. As tensins couple the extracellular and intracellular environment, they are involved in cell-matrix communication. EGF may influence the actin cytoskeleton via induction of "tensin-3-tensin-4 switch" [47]. This phenomenon is described as downregulation of tensin-3 and upregulation of tensin-4, which results in increased cell migration and metastasis of cancer cells. Targeting tensin-4 in cancers may be a promising approach to find beneficial treatment as tensin- 4 is involved in crucial signaling pathways, e.g. the EGFR-dependent signaling pathway.

A study conducted by Qi et al. [13] indicated that tensin-4 promotes cancer progression via the Akt/GSK-3 $\beta /$ snail signaling pathway. Overexpression of tensin-4 commonly observed in cancers contributed to upregulation of phosphorylated forms of Akt, GSK-3 $\beta$ and Snail and vimentin, while expression of E-cadherin was downregulated. Loss of E-cadherin and gain of $\mathrm{N}$-cadherin, vimentin and fibronectin are typical markers of EMT [17]. Another pathway involved in EMT induction is the TGF- $\beta 1$-mediated axis. Asiri et al. reported that tensin-4 mediates TGF- $\beta 1$-dependent EMT. It is likely that the relation between TGF- $\beta 1$ and tensin- 4 may rely on integrins as TGF- $\beta 1$ activates integrin and tensin- 4 binds to its cytoplasmic tail [48]. Stabilization of Src may provide another mechanism responsible for tensin-4-mediated 
EMT. In colorectal cancer tensin-4 regulates Src expression through upregulation of the Akt/ mTOR/4E-BP1 pathway or downregulation of calpain-dependent Src proteolysis [19]. All aforementioned findings suggest that targeting tensin- 4 in cancer treatment may be a promising therapeutic approach.

\section{Tensins in cancers}

So far, very few studies have been conducted to assess the expression of tensin- 1 to -3 in tumors at the level of both genes and proteins. To date, the levels of gene or protein expression have been assessed in 8 cancer types: melanoma, breast, kidney, bladder, colorectal, liver, lung and prostate cancer. The roles of tensins 1-3 were evaluated using various in vitro models including human breast cancer cell lines, murine breast cancer cell lines, colorectal cancer cell lines, melanoma cell lines and human glioblastoma cell lines. There are more reports describing the expression of tensin- 4 in tumors, at both the gene and protein levels. Differences in tensin-4 expression were detected in 7 cancers (colorectal, breast, prostate, liver, gastric, pancreatic cancer and thymoma). There have also been studies attempting to identify the role of tensin-4 in carcinogenesis, using both in vitro and in vivo models. Human and murine cellular models comprised colorectal cancer cell lines, lung adenocarcinoma cell lines, prostate cancer cell lines, pancreatic cancer cell lines and human hepatoma cell lines. An in vivo study included mice injected with HCT116 cells expressing tensin-4. To date, there is no clinical trial targeting tensins as their impact on carcinogenesis is not fully established. Since tensin-4 affects EGFR degradation, which in turn, is overexpressed in many cancers, it is likely that tensin-4-targeted trials may be carried out in the future.

Further information considering the evaluation of the role of tensins in cancers is provided below. In this section we present the results from research on tensins 1-4 depending on cancer type. To explain the results thoroughly we provide information on the number of subjects, control group and clinicopathological correlations as well the relationship with clinical outcome.

\section{Tensin-1}

\section{Breast cancer}

Kotepui et al. [49] conducted an analysis of mRNA expression in 33 patients with ductal breast cancer, using quantitative PCR (qPCR). The expression was then correlated with clinical and pathological parameters (patients' age, tumor size, axillary lymph node infiltration, triple-negative breast cancer status). In $85 \%$ of the patients a reduced level of mRNA tensin-1 expression was observed in tumor cells compared to normal cells. However, based on the obtained results, no statistically significant correlation was noted between tensin-1 expression and the selected clinicopathological parameters.

Zhan et al. [50] used 7 breast cancer cell lines (SKBR3, HCC1500, T47D, BT474, MCF-7, MDAMB-231 and MDA-MB-468 cell lines) to identify a new mechanism involved in the metastasis of this cancer type. As a control, the non-tumorigenic epithelial MCF-10A cell line was used. In addition, the authors tested the level of tensin-1 expression from 104 breast cancer samples and correlated it with metastasis and survival rate. The process of metastasis results from stimulated expression of single-stranded microRNA (miR548j), mediated by tensin-1. This protein, as an intermediary between the ECM and cell skeleton, is displaced to the focal adhesion site, thus stimulating the signaling pathways facilitating cell motility and increasing the invasiveness of the tumor mass. It has been proven that tensin- 1 is an important factor in the proper process of cell migration. Moreover, it has the ability to suppress tumors by inhibiting excessive migration of cancer cells via targeting DLC-1, known as a tumor suppressor involved in cytoskeleton organization and maintaining cell morphology. Dissociation of DLC1-tensin-1 complex at focal adhesion causes loss of suppressive properties of DLC-1, promoting cancer cell growth [51]. Another critical factor for regulation of cell migration and inhibition of invasion is protein phosphatase $1 \alpha$ (PP1 $\alpha$ ), which negatively regulates tumor development. Binding of PP1 $\alpha$ to tensin1 leads to its dephosphorylation and thus limits cancer invasiveness. PP1 $\alpha$ seems to represent a novel mechanism for control cell function independently of RhoGAP DLC-1 [52]. In addition, by conducting examinations based on qPCR on human breast cancer tissues, the authors showed that the level of tensin-1 expression decreased in patients with tumors metastasized to nearby lymph nodes. These results led to the conclusion that tensin- 1 is a negative regulator of breast cancer cell invasiveness. Furthermore, the same authors used microarray technology to evaluate the expression of tensin-1 in breast cancer. They correlated the obtained results with the survival rate of patients and, based on the results, demonstrated a significant relationship between the expression of this protein and time free from distant metastases. High expression of tensin-1 favored prolongation of survival without metastases. Moreover, the study showed that tensin-1 expression was significantly reduced in cases of metastatic breast cancer as compared to patients in whom no metastases occurred. 


\section{Renal cancer}

Martuszewska et al. [53] performed an analysis of mRNA expression of the TNS1 gene in 260 patients with renal cancer and correlated it with clinicopathological features such as gender, patients' age, tumor type, size and grade, TNM stage, venous and regional lymph node invasion. Matched normal kidney tissues served as a control. The results showed a significant correlation between the level of expression and tumor severity: the expression of mRNA decreased with an increase in tumor severity. However, there was no significant correlation between the expression of the gene encoding tensin-1 and other clinicopathological parameters.

\section{Colorectal cancer}

In the study on a colorectal cancer cell model (SW620 and RKO lines), Zhou et al. [54] assessed TNS1 gene expression and compared it with normal cells represented by the FHC cell line. In addition, the authors carried out an analysis of survival of transgelin and tensin-1 in colorectal cancer patients (data from The Cancer Genome Atlas (TCGA) database, number of subjects not included). They observed increased expression of tensin-1 mRNA, which correlated with increased migration of cancer cells. Based on the results, they defined tensin-1 as an oncogene in the development of colorectal cancer, with potential prognostic value. However, the mechanism regulating the expression of this protein in cancer cells is still unknown. In their study, the authors proposed transgelin as a factor inducing tensin-1 expression. They demonstrated that the expression of these proteins is increased in colorectal cancer in both in vitro and in vivo models. The analysis of survival rate showed a statistically significant correlation between the expression of transgelin and tensin-1 and a low survival rate in patients with colorectal cancer. Based on these results, it is suggested that activation of the transgrelin-tensin-1 axis may be an important biochemical pathway in promoting the proliferation and migration of colorectal cancer cells.

\section{Bladder cancer}

Zhang et al. [55] performed an analysis of the TCGA-BLCA database containing gene expression data in a number of cancers and enabled identification of the gene that encodes tensin- 1 as one of the genes with prognostic potential to facilitate stratification of bladder cancer patients (number of cases not included). They correlated the level of tensin-1 expression with overall survival and patient status (alive/deceased). It was found that the level of tensin-1 expression was significantly higher in deceased patients with bladder cancer compared to living patients. Moreover, tensin-1 expression patterns were correlated with the total survival rate of patients, revealing a negative correlation.

\section{Prostate cancer}

Bioinformatic analysis was also used by Zhu et al. [56] to search for factors involved in the process of prostate cancer metastases to bones, based on data from the Gene Expression Omnibus database. Based on databases (ID GSE21036, GSE32269 GSE77930, Exo), the authors analyzed molecular signatures of 67 PC patients with bone metastasis and compared them to 150 primary prostate cancer samples. As a result of the performed analyses, they found that tensin- 1 can be a molecular target of miR-636 and promote bone metastases. Based on the analysis of mRNA tensin-1 expression, they observed a statistically significant negative correlation between miR-636 and tensin-1 expression levels. The level of tensin-1 expression was elevated in prostate cancer tissues compared to normal tissues. A similar correlation was found between the level of tensin-1 gene expression in primary prostate cancer and its metastases to bones, where mRNA expression level in metastatic cells was considerably higher. Moreover, the analysis of tensin-1 expression and remission parameters (no biochemical features of the disease, disease-free period) revealed considerable prognostic usefulness of tensin- 1 .

\section{Tensin-2}

\section{Renal cancer}

Martuszewska et al. [53] compared the expression of tensin-2 mRNA in cancer lesions collected from 223 patients with clear cell, papillary and chromophobe types of renal cell carcinoma and renal oncocytoma to normal renal tissue. Additionally, the level of tensin-2 mRNA was correlated with clinicopathological parameters (gender, patients' age, tumor size, its stage, TNM classification, histological type of cancer, infiltrates to blood and lymphatic vessels, metastases to nearby lymph nodes). The performed analysis showed a reduced level of tensin-2 mRNA expression in clear cell and papillary renal cell carcinoma compared to normal tissue. The authors observed no significant relationships between the selected clinical features and the level of tensin-2 mRNA expression.

\section{Liver cancer}

The relationship between the overexpression of tensin- 2 variant 3 and hepatocellular carcinoma invasiveness was evaluated by Wai Ping Yam et al. [57]. In 50 patients with liver cancer, they analyzed 
the correlation of clinicopathological parameters with the expression of variant 3 of tensin- 2 mRNA. In the process of combining mRNA transcripts (alternative splicing), different protein-coding variants may be formed. There are 3 alternative splic ing variants of tensin-2. It has been demonstrated that variant 3 promotes fibroblast migration [9]. To evaluate the relationship between this genetic variant and clinicopathological features the authors considered infiltration to blood vessels, occurrence of microsatellite instability, tumor encapsulation (surrounding the cancer with a thin layer of the tissue), hepatitis B virus (HBV) infection, degree of cell differentiation, tumor size, number of lymph nodes under neoplastic processes, co-occurrence of cirrhosis and the tumor stage according to the PTNM scale. The authors did not correlate the expression of variant 3 of tensin- 2 with survival rate. The researchers noted increased expression of tensin-2 in neoplastic tissue compared to normal tissue. Moreover, an increased level of tensin-2 mRNA expression was significantly more frequent in patients with infiltration to blood vessels and microsatellite instability as well as in those with hepatocellular carcinoma without encapsulation. Based on the obtained results, it can be concluded that the overexpression of variant 3 of tensin- 2 mRNA was associated with a more aggressive type of cancer.

\section{Various types of cancer}

According to the data obtained from databases, Hong et al. [58] analyzed the expression of tensin-2 mRNA in various cancers (bladder, breast, lung, brain, cervical, colorectal, esophageal, gastric, head and neck, kidney, liver, ovarian, pancreatic, prostate cancer, leukemia, melanoma, lymphoma, myeloma, sarcoma and other cancers). The authors compared the level of tensin- 2 expression from 6 datasets between normal tissue and corresponding cancer lesions as follows: 231 pairs of normal and liver cancer, 119 pairs of normal and esophageal squamous cancer, 43 pairs of normal and breast cancer, 32 pairs of normal and colorectal cancer, 22 pairs of normal and head and neck cancer, and 20 pairs of normal and lung adenocarcinoma. They found that in head and neck squamous cell carcinoma, esophageal squamous cell carcinoma, breast cancer, lung adenocarcinoma, hepatocellular carcinoma and colorectal carcinoma the expression of the tensin-2 gene is significantly reduced compared to normal cells. Furthermore, they compared the level of tensin-2 expression with survival rates based on the results of studies including over 150 patients and an observation period not less than 5 years. Based on the performed analyses they demonstrated that low tensin-2 expression correlates with a short survival period without relapse in the case of breast and lung cancer.

Martuszewska et al. [53] made an attempt to determine the level of mRNA expression in vitro, performing analyses of cancer-derived cell lines from various tissues. In the study the authors used cellular models for breast cancer (MCF-7, MDA-MB-231), cervical cancer (HeLa S3, Int407), colorectal cancer (SW480), melanoma (WM9, WM266-4, WM793), non-small lung cancer (H358, H2087, H226, H727), osteosarcoma (U20S), prostate cancer (DU145, PC3, PNT-1A), B cell lymphoma (U629, U2932) and T cell leukemia (Jurkat) as well as normal cell lines such as dermal fibroblasts (AG52), human umbilical vein cell line (EAhy926), normal breast epithelial cell line (MCF-10A) and renal proximal tubular cell line (HK-2). As a result of the in vitro assays, they noted that the TNS2 gene was absent in the majority of the analyzed lines except for SW480 colorectal cancer line, which showed tensin-2 mRNA expression at a detectable level.

\section{Tensin-3}

\section{Breast cancer}

Shinchi et al. [59] evaluated the level of tensin-3 expression in breast cancer via the immunohistochemical method using commercially available breast cancer and normal tissues (number of samples not included). In addition, the authors tested the impact of tensin-3 on cancer invasiveness in the MDA-MB-231 breast cancer cell line exhibiting potent metastatic properties. They observed moderate expression of this protein on the apical side of epithelial cells, whereas a strong immunohistochemical reaction occurred in the cytoplasm of breast cancer cells or cells adjacent to the cancer cells. Tensin-3 overexpression was observed in over $60 \%$ of cancer cells. Moreover, in the MDAMB-231 line of breast cancer cells, the authors demonstrated that the silencing of the gene encoding tensin-3 reduced the invasiveness of these cells. Such results suggest that tensin-3 triggers the invasiveness of breast cancer cells.

Qian et al. [60] evaluated the contribution of tensin-3 to tumorigenesis and metastasis in breast cancer models (human and murine) and reported a previously undescribed mechanism responsible for these processes. The authors examined the process of tyrosine phosphorylation in the $\mathrm{SH} 2$ domain of tensin-3 through creating a mouse model of breast cancer, in which they assessed the level of tensin-3 expression and tyrosine phosphorylation in the $\mathrm{SH} 2$ domain. They compared the obtained results to normal mammary gland cells in which the level of tyrosine phosphorylation was almost undetectable. Sim- 
ilar results were observed in the MDA-MB-468 line of human breast cancer. The use of the tensin-3 expression silencing sequence showed that, under in vitro conditions, tensin-3 is biologically important in cancer formation and metastasis. In Met-1 and PyMT cell lines, tumor growth was inhibited independently of anchoring, and the tumor formation process occurred after orthotopic injection of cells. These results prove that tensin-3 is phosphorylated by Src in the cell model of advanced breast cancer, entailing cancer formation and metastasis. Tyrosine phosphorylation in the $\mathrm{SH} 2$ domain of tensin- 3 by Src may increase the migration of cancer cells, giving the cancer a metastatic potential.

\section{Renal cancer}

Martuszewska et al. [53] correlated the level of mRNA expression of the TNS3 gene in 260 patients with renal cancer with clinicopathological parameters such as gender, patients' age, tumor type, size and grade, TNM stage, venous and regional lymph node invasion. Normal kidney tissues were used as a control tissue. They demonstrated that in patients with clear cell renal cell carcinoma, tensin-3 membrane expression in cancer cells shows a statistically significant correlation with survival rates. The opposite was true for the cytoplasmic reaction, in which such a correlation was not observed. Moreover, the analysis of tensin-3 mRNA expression showed a statistically significant correlation with tumor stage. However, no correlation was observed between tensin-3 expression and other clinicopathological parameters, such as tumor size, infiltration to blood vessels, infiltration of the nearby lymph nodes, patients' age and gender. Furthermore, in the same study the authors demonstrated that in vitro overexpression of tensin-3 does not affect the proliferation of tumor cells, although it significantly reduces their migration.

Carter et al. [61] assessed the level of methylation of the TNS3 promoter region in human renal cancer cell lines (HK-2 and HEK293) and compared it with the level of tensin-3 expression. As a positive control (methylated) they used genomic DNA from HEK293 cells, while genomic DNA from the human glioma cell line SNB-19 served as a negative control (unmethylated). They observed a significantly elevated methylation level in renal cancer samples vs. normal kidney cells. After a quantitative analysis of differences in methylation levels of CpG 2 and 8 islands in cancer and normal samples, the authors tested the effect of the demethylation process on the level of tensin-3 expression. As a result, they observed a 3 times higher level of tensin-3 mRNA expression compared to the control cells (not demethylated). The analysis of methylation levels of CpG 2 and 8 islands and tensin-3 mRNA expression showed a statistically significant negative correlation between the expression of tensin-3 mRNA and the methylation level of CpG 2 islands. There was no statistically significant association between the expression of tensin-3 and CpG 8 methylation level. This finding may indicate an epigenetic mechanism explaining the cause of reduced expression of tensin-3 in renal cancer.

\section{Melanoma}

Martuszewska et al. [53] used a melanoma cell model for assessment of cancer cell migration. They chose the WM793 melanoma cell line for their experiments due to the high level of endogenous tensin-3, at which accelerated migration of cancer cells was observed. Next, the researchers applied the tensin-3 expression silencing sequence, which entailed about a $30 \%$ increase in WM793 cell migration compared to the control cells. It was noted that tensin-3 gene expression silencing enhanced the migration capacity of cancer cells.

Similarly to the study of Martuszewska et al. [53], Qian et al. [60] evaluated tensin-3-dependent cell migration in metastatic melanoma cell lines (mel 553B, mel 1088 and mel 568). Silencing tensin-3 resulted in strong inhibition of cancer cell growth and migration.

\section{Glioblastoma multiforme}

Chen et al. [62] tested contribution of tensin-3 to cell migration, invasion and morphology in an in vitro model of human glioblastoma (05MG, U251 and GBM8401 cell lines). Then, they analyzed the expression level of RNA-binding protein Musashi-1 (MSI1) and tensin-3 in samples from patients with glioblastoma (data from TCGA database, 330 individuals). Based on data from this database, they established a ratio of MSI1/tensin-3 and performed survival analysis of glioblastoma patients. They demonstrated that tensin-3 significantly contributed to development of glioblastoma, in which increased expression was observed. As MSI1 is involved in numerous processes in the cell, e.g. maintaining the pluripotency of stem cells as well as the ability of self-renewal, MSI1 promotes cell migration, but the mechanism is still unknown. However, it has been demonstrated that MSI1 binds to the a3'UTR (three prime untranslated region) of tensin-3 mRNA. The effect of the connection is inhibited translation of tensin-3. Analysis of clinical samples revealed that the level of tensin-3 expression is inversely proportional to that of MSI1, i.e. MSI1 overexpression leads to a decrease in tensin-3 expression level. What is more, tensin-3 was expressed in the tumor 
tissue, but not its metastases. The survival analysis showed that patients with a high ratio of MSI1/ tensin-3 had higher risk of a poor outcome. Taken together, a consequence of reduced tensin-3 expression in the glioblastoma is increased cell migration. This phenomenon may be explained by a disturbed signal transduction pathway involving tensin-3 effector proteins, i.e. RhoA-GTP, that are activated during reduced tensin-3 expression, leading to changes in cell morphology by dysregulation of the cell cytoskeleton and changes in cell polarization or mobility. The authors concluded that the inverse relation between MSII and tensin-3 may serve as a predictor for metastatic potential of glioblastoma and clinical outcome of patients.

\section{Tensin-4}

\section{Colorectal cancer}

Albasri et al. [63] evaluated the relationship between the level of tensin- 4 expression and clinicopathological parameters in 462 cases of colorectal cancer. The researchers considered the following: patients' age, gender, histological type of cancer, its stage, size of the tumor, stage according to the Dukes classification, lymph node metastasis, infiltration to blood vessels and the presence of distant metastases. In addition, they analyzed the correlation between tensin- 4 expression and survival rate. Using colorectal cancer cell models (HT116 and SW620 cell lines expressing low and high tensin-4 expression, respectively), the authors assessed the role of tensin-4-related cell migration while to test the impact of tensin-4 on metastasis, they used an in vivo mouse model. It is worth mentioning that colorectal cancer cell lines express tensin- 4 at various levels as demonstrated in another study conducted by Albasri et al. [18]. The authors tested the level of mRNA tensin-4 expression in 29 colorectal cancer lines, and in the selected cancer cell lines tensin-4 expression decreased in the following order: DLD1, Colo 205, LoVo, SW620, COLO201, C80, GP2D, VACO10MS, C32, C84, HCA46, SW1116, VACO5, C125, LS1034, SW1222, SW480, SW948, C106, COLO320DM, HT29, HT55, RKO, HCA7, HCT116, HUTU80, HRA19, Caco-2 and SW837. Statistical analysis of clinical samples revealed that a high level of tensin-4 expression correlates with more advanced colorectal cancers, lymph node metastases, vascular infiltration and distant metastases. Moreover, patients with overexpression of the protein had a lower total survival rate. However, the authors did not confirm the role of tensin- 4 as a prognostic marker in colorectal cancer. Instead, they presented evidence of increased mobility of colorectal cancer cells under conditions of increased tensin-4 expression in a cell model study. They confirmed this phenomenon also in vivo by injecting cells with increased tensin-4 expression into mice. In animals with overexpression of tensin-4, there were both local colorectal cancer foci and metas tases to the spleen and liver. It was also observed that the survival rate of mice with tensin-4 overexpression was significantly lower.

Asiri et al. [19] also examined the relationship between the level of tensin-4 expression and clinicopathological parameters (tumor severity, stage, presence of lymph node metastases, infiltration to blood vessels, stage in the Dukes classification and presence of mutations in the KRAS gene) in 84 samples. However, they did not observe any correlations between the protein expression level and the examined factors.

Al-Ghamdi et al. [64] conducted research on colorectal cancer cell lines including SW620, DLD1, Colo 205, RKO cell lines, in which they examined the mechanism of interaction of tensin-4 with $K R A S / B R A F$ genes: they silenced the expression of the KRAS gene and observed a considerable decrease in tensin-4 expression and, consequently, decreased cell motility.

Albasri et al. [18] examined the mechanism by which tensin-4 develops and facilitates metastasis by inhibiting the expression of E-cadherin using colorectal cancer cell models (HT116 and SW620 cell lines) HT116 expresses low tensin-4 expression while SW620 exhibits a high expression level. In addition, the authors assessed the expression of tensin-4 in 29 colorectal patient samples in comparison with normal tissue that originated from tumor edges. Their research on colorectal cancer cell lines via the qPCR technique showed an over twofold increase of tensin-4 mRNA expression in tumor cells compared to normal cells. According to their results, tensin-4 promotes epithelial-mesenchymal transformation and inhibits the expression of E-cadherin. Immunohistochemical staining for tensin-4 displayed a positive reaction in $69 \%$ of cases, suggesting that tensin- 1 acts as an oncogene.

Thorpe et al. [65] also studied the mechanisms responsible for the development of tensin-4 expression in colorectal cancer lines (HCT116, Caco-2 and SW620 cell lines). The results of their tests on colorectal cancer cell lines showed that the expression of this protein is stimulated by EGFR and KRAS, but inhibited by STAT3 protein.

Another study, conducted by Liao et al. [66], focused on the influence of tensin- 4 on $\beta$-catenin and used colorectal cancer cell models such as SW480, SW620, HT29, HCT116 and LoVo. As a control normal fetal colonic mucosa (FHC cell line) was used. The researchers noted that expression of this protein occurs mainly in the cell nucleus. 
In qPCR studies, they demonstrated an over fourfold increase in tensin-4 expression in colorectal cancer cells compared to normal colorectal cells. They also observed a relationship between nuclear expressions of tensin- 4 and $\beta$-catenin. However, no such dependency in the cytoplasmic presence of these proteins was observed. The existence of the above-mentioned correlation indicates the role of tensin-4 in the canonical Wnt pathway.

Hong et al. [67] focused on nuclear location of tensin-4 in SW480 colorectal cancer cells. They found that overexpression this protein stimulates cell growth and proliferation of colorectal cancer cells.

\section{Gastric cancer}

In the analyzed literature we found 3 papers on expression of the tensin- 4 gene mRNA and tensin-4 protein in gastric cancer. Sakashita et al. [68] conducted a study on tissues from 114 patients with diagnosed gastric cancer and on 5 human gastric cancer cell lines (MKN1, MKN7, MKN28, MKN45, and MKN74 cell lines), using the $\mathrm{qPCR}$ and IHC methods. Normal mucosa samples served as a control for $\mathrm{IHC}$ examination. Tensin-4 mRNA expression was correlated with clinicopathological parameters including patients' age, gender, histological type, serosal invasion, lymph node metastasis, lymphatic permeation, distant metastasis, venous infiltration, peritoneal dissemination and patient status (alive/deceased). Next, they analyzed mRNA tensin-4 expression and survival rate. As a result, they noted increased tensin-4 mRNA in tumor cells compared to normal gastric mucosa. These findings were confirmed by tensin- 4 expression tests via the IHC method, which indicated increased expression of this protein in neoplastic tissue compared to normal gastric mucosa. Moreover, they found a relationship between the expression of mRNA and histo-clinical parameters. They demonstrated statistically significant correlations between increased expression of tensin- 4 and a lower degree of differentiation, infiltration to the serosa, lymph node metastases, peritoneal carcinomatosis and cancer-related death. Additionally, they observed that increased tensin-4 gene expression was associated with a shorter total survival time.

The study by Sawazaki et al. [69] revealed similar results to those presented by Sakashita et al. [68]. The researchers performed tests on 134 tissue samples with stage II and III which constituted $70 \%$ of gastric cancer cases. Normal gastric mucosa was used as a reference. The authors analyzed tensin-4 expression with the following clinicopathological features: patients' age, gender, tumor size, histological type, serosal invasion, lymph node metastasis, lymphatic invasion, venous invasion and TNM stage. Using the Kaplan-Meier method, they correlated postoperative survival rate with the level of tensin- 4 expression. They also evaluated mRNA tensin -4 expression in human gastric cancer cell lines (MKN1, MKN7, MKN45, MKN74, NUGC3, NUGC4, and Kato III); however, the authors did not provide control cells, e.g. a normal gastric cell line. Their results confirmed increased tensin-4 expression in cancer tissues compared to normal gastric mucosa. The expression of tensin-4, measured by the IHC method, was higher in neoplastic tissue both in the differentiated and undifferentiated cancer type. The expression was mainly observed in the cytoplasm of cancer cells. Moreover, the authors analyzed the relationship between mRNA expression of tensin- 4 gene and clinicopathological parameters, but did not find any statistically significant correlations. However, they proved that increased tensin- 4 expression results in shorter total survival time. These studies confirm that the expression of tensin- 4 is associated with more advanced gastric cancers with worse prognosis and a lower total survival rate. Based on these results we can conclude that the presence of this protein stimulates cell proliferation and migration. Moreover, the authors suggested that tensin-4 may be an independent factor, both prognostic and predictive, in gastric cancer.

The study performed by Qi et al. [13] evaluated tensin-4 expression in 80 gastric cancer samples and matched normal gastric tissue. The authors correlated the tensin-4 expression with clinicopathological features including gender, patients' age, cancer location, differentiation, tumor size, depth of infiltration, lymph node metastasis and TNM stage. In addition, they analyzed the relation between tensin-4 expression and survival rate. Gastric cancer cell models (SGC7901, MKN45, and MKN28 cell lines) and clinical specimens were used to assess mRNA tensin-4 expression. The GES-1 non-tumorigenic human gastric epithelial cell line was used as control gastric cells. Immunohistochemical analysis revealed a significant correlation between tensin-4 expression and depth of infiltration (intramucosa, submucosa, muscular layer and full layer), lymph node metastasis and TNM stage. Analysis of survival rate indicated that patients with higher tensin-4 expression had a worse prognosis and shorter survival time. The level of mRNA tensin-4 expression was significantly higher in gastric cancer samples (cell lysates and patients' specimens) than that in normal gastric samples (non-tumorigenic gastric cell lysate and normal mucosa).

\section{Lung cancer}

In the literature there are also reports on the relationship between tensin- 4 and the pro- 
gression of small-cell lung cancer. Sasaki et al. [70] assessed the level of tensin-4 mRNA expression in 89 patients with lung cancer and correlated it with clinicopathological characteristics such as mean patients' age, patients' age, gender, clinical stage, $T$ status, lymph node metastasis and histological type. The study group consisted of cases of squamous cell carcinoma, adenocarcinoma and small cell carcinoma. Adjacent normal lung tissues served as a control. The analysis of the protein expression level vs. clinical features showed a positive correlation of tensin-4 expression with $\mathrm{T}$ category of lung cancer. The expression increased along with the cancer severity. They found a significant correlation between tensin-4 expression and histological type of lung cancer: mRNA tensin-4 expression in squamous cell carcinoma was higher than in adenocarcinoma.

Lu et al. [20] used lung adenocarcinoma cell models (A549 and NCl-H1299 cell lines) to investigate the effect of tensin-4 on cell migration and invasion as well as EMT. They observed that an increased level of tensin- 4 expression is a factor facilitating cell migration. The authors found that at both transcriptional and post-transcriptional levels the overexpression of this protein stimulates $\mathrm{N}$-cadherin and vimentin, and lowers the E-cadherin level. These proteins play a significant role in regulating the epithelial-mesenchymal transformation, which indicates that tensin- 4 is involved in this process and thus promotes increased migration and invasiveness of the tumor mass.

Moreover, Bennett et al. [71] conducted a study on lung cancer cells (H125, H358, H441 and A549 cell lines) which were stimulated by EGF. They discovered that such stimulation leads to the expression of STAT3, which induces tensin-4 expression. In the next stage of the research, they silenced tensin-4 expression, thus considerably decreasing the invasiveness of lung cancer cells.

\section{Breast cancer}

Albasri et al. [72] conducted research on tensin-4 expression in 1409 breast cancer samples. The authors analyzed the level of tensin- 4 expression with clinicopathological parameters such as patients' age, menopausal status, histological type and grade, tumor size, lymph node metastasis, Nottingham Prognostic Index (NPI), venous invasion, local and regional recurrence and distant metastases. Normal epithelial breast tissue served as a control. The Kaplan-Meier method was used to assess the correlation between tensin- 4 expression and survival rate. They demonstrated that this protein does not occur in normal breast epithelium, but can be found in cancer-changed cells. Tensin-4 appeared in the cytoplasm of can- cer cells, but the authors did not observe its membrane expression. The results of their study indicated a statistically significant correlation of high tensin-4 expression with larger tumors $(>1.5 \mathrm{~cm}$ ), their higher stages, metastases to the nearby lymph nodes, occurrence of local and surrounding recurrences, higher NPI, histological type of cancer and distant metastases. Moreover, the authors reported that increased tensin-4 expression is associated with worse prognosis.

\section{Prostate cancer}

Yang et al. [73] assessed the level of tensin-4 expression in the cell model of prostate cancer (PC-3 cell line) in comparison with RWPE-1 cells representing normal prostate tissue. Using the Grasso prostate dataset and GSE3325 gene expression dataset set of Grasso prostate, the authors analyzed the level of tensin- 4 expression between 3 groups: benign prostate, primary cancer and metastatic cancer. The first dataset included 122 cases while the second dataset included 19 cases. The authors discovered that the level of tensin-4 expression significantly decreased as cancer progressed. After comparing the protein expression level and the degree of prostate cancer progression, the authors concluded that tensin-4 expression level decreases with the progression of prostate cancer. Moreover, the researchers observed that the loss of tensin- 4 in prostate epithelial cells entails decreased cell adhesion. Consequently, increased cell motility may facilitate the acquisition of mesenchymal cell characteristics by these cells. Furthermore, tensin- 4 dysfunction in prostate epithelial cells may significantly contribute to neoplastic transformation.

Li et al. [74] used immunohistochemistry to test the expression of tensin- 4 in 72 prostate cancer samples in comparison with normal prostate tissue and then correlated it with the Gleason score. They observed a decrease or lack of tensin-4 expression in prostate cancer lesions as opposed to high tensin-4 expression in normal epithelial cells. They also observed the presence of tensin- 4 spaces surrounding the cancer cells. The researchers analyzed the relationship between the protein expression level and the degree of histological differentiation according to the Gleason grading system. Statistical analysis showed that tensin-4 expression decreased with increased degree of tumor differentiation.

\section{Pancreatic cancer}

Al-Ghamdi et al. [43] conducted tests on 44 pancreatic cancer tissue samples and cell culture lines (Capan-2, Colo357, Panc-1 and PSN-1) evaluating tensin-4 expression. Among these cell lines tensin-4 expression in Capan-2 and Panc- 1 cell lines were not observed, while Colo357 and Panc-1 
showed strong expression. For further investigation Panc-1 and PSN-1 were selected. It was found that tumor lesions displayed higher expression of tensin-4 compared to non-neoplastic pancreatic tissue. The results of the study on cell models indicate that tensin-4 serves no role in cell proliferation, but participates in colony formation and stimulates cell migration.

\section{Hepatocellular carcinoma}

Chan et al. [75] performed tests on hepatocellular carcinoma cell lines (SMMC-7721, and BEL7402 HLE and PLC cell lines) and 30 tissue specimens with this type of tumor assessing tensin-4 expression. The LO2 cell line was used as a normal hepatocyte cell line whereas non-tumor liver tissue served as a reference. The clinicopathological data about individuals included gender, patients' age, tumor size, other liver conditions, tumor microsatellite formation, tumor encapsulation, venous infiltration, differentiation grade and TNM stage. Immunohistochemical analysis showed the presence of tensin- 4 in $43 \%$ of tissues with the said cancer. Cells in culture were stimulated by their EGF, after which they showed considerably higher tensin-4 expression. The results of the study indicate that this is due to activation of ERK1/2 by EGF, which entails increased expression of tensin- 4 and indicates the role of this protein in cancer cell proliferation and migration.

\section{Melanoma}

Sjoestroem et al. [76] examined the expression of tensin-4 in 445 patients with melanoma and correlated it with clinicopathological data such as patients' age, gender, tumor size, ulceration, tumor subtype, location, metastases as well as gender, location and American Joint Committee on Cancer (AJCC) stage for metastatic melanoma. The Kaplan-Meier test was used for evaluation of the relation between tensin- 4 expression and overall and 5 -year survival rate in melanoma patients. They divided their study group into 4 categories: healthy patients, those with precancerous lesions, patients with cancer without metastases and people with melanoma plus metastases. The authors noted that the protein expression was higher in precancerous lesions compared to patients without melanoma, and that tensin-4 expression was higher in patients with primary cancer compared to the subjects with precancerous lesions. However, the researchers did not observe any relationships between tensin-4 expression in primary cancer and metastases. Their results confirm that the expression of tensin-4 increases with melanoma progression. Moreover, higher tensin-4 expression is observed in tumors with a larger diameter. Additionally, increased ex- pression of this protein correlates with shorter total survival time in patients with primary cancer as well as those with tumor of $\geq 1 \mathrm{~mm}$ diameter. The authors summarized that tensin- 4 may act as an independent prognostic factor in patients with primary melanoma.

\section{Thymoma}

Sasaki et al. [77] conducted a study assessing the level of mRNA tensin- 4 expression in 45 thymoma tissues. They compared the level of tensin- 4 expression with clinical data (mean patients' age, patients' age, gender cancer stage, myasthenia gravis, histological type and lymphocyte infiltration). Normal thymus samples were used as a control. They discovered that in tissues from patients with thymoma the level of tensin-4 expression increased with this lesion's severity. This may indicate that tensin-4 is involved in thymoma progression.

Table I summarizes the clinical significance of tensin-1, -2, -3 and -4 expression associated with clinicopathological parameters such as tumor progression, metastases or survival.

\section{Conclusions and implications for future research}

Although understanding of cellular functions of tensin-family proteins is of emerging interest, their clinical significance needs to be explored thoroughly. The question about the general role of these proteins in carcinogenesis still remains unanswered. The differences in the expression level (decrease or increase) of tensins among cancers indicate that they may serve as either a cancer-promoting or cancer-inhibitory factor. There are several reports presenting tensin-dependent processes, such as cell adhesion, migration, cytoskeletal maintenance and communication with extracellular matrix. Further studies on the relationship between tensins and integrins, actin fibers or intracellular kinases (FAK, PI3K) may contribute to a deeper understanding of the regulation of signal transduction inside and outside of a cell. Not only do tensins integrate ECM with the actin cytoskeleton, but they also regulate Rho GTPase, EGFR and c-Met signaling pathways. As EGFR is overexpressed in various tumors, it is intriguing whether the link between tensins and this receptor may be a potential biomarker or even contribute to finding beneficial anti-cancer therapy. Forthcoming publications will shed new light on the role of tensin-family adhesion proteins in cancerogenesis.

\section{Funding}

This study was supported by the Medical University of Bialystok, grant no. SUB/1/DN/19/002/ 3314. 
Table I. Selected reports presenting the clinical significance of tensins associated with clinical features. The data display how protein expression changed depending on cancer type. In addition, research methodology, and significant correlations between tensins and clinicopathological parameters are summarized.

\begin{tabular}{|c|c|c|c|c|c|}
\hline $\begin{array}{l}\text { Protein/ } \\
\text { Publication }\end{array}$ & Cancer & $\begin{array}{l}\text { Number of } \\
\text { subjects }\end{array}$ & $\begin{array}{l}\text { Expression } \\
\text { in cancer }\end{array}$ & Method & Significant correlations \\
\hline \multicolumn{6}{|l|}{ Tensin-1 } \\
\hline $\begin{array}{l}\text { Kotepui et al. } \\
{[49]}\end{array}$ & $\begin{array}{l}\text { Breast } \\
\text { cancer }\end{array}$ & 33 & $\begin{array}{l}\text { Negative in } 85 \% \\
\text { tumors }\end{array}$ & qPCR & No correlations \\
\hline $\begin{array}{l}\text { Zhan et al. } \\
\text { [50] }\end{array}$ & $\begin{array}{l}\text { Breast } \\
\text { cancer }\end{array}$ & 104 & Low & $\mathrm{IHC}$ & $\begin{array}{l}\text { High expression correlates with longer } \\
\text { metastasis-free survival, lower expression } \\
\text { observed in metastasis }\end{array}$ \\
\hline $\begin{array}{l}\text { Martuszewska } \\
\text { et al. [53] }\end{array}$ & $\begin{array}{l}\text { Renal } \\
\text { cancer }\end{array}$ & 260 & $\begin{array}{l}\text { Positive in all } \\
\text { tumors }\end{array}$ & qPCR & $\begin{array}{l}\text { Expression of mRNA decreased with } \\
\text { an increase in tumor severity }\end{array}$ \\
\hline \multicolumn{6}{|l|}{ Tensin-2 } \\
\hline $\begin{array}{l}\text { Martuszewska } \\
\text { et al. [53] }\end{array}$ & $\begin{array}{l}\text { Renal } \\
\text { cancer }\end{array}$ & 223 & $\begin{array}{l}\text { Positive in all } \\
\text { tumors }\end{array}$ & qPCR & No correlations \\
\hline $\begin{array}{l}\text { Way Ping Yam } \\
\text { et al. [57] }\end{array}$ & $\begin{array}{l}\text { Liver } \\
\text { cancer }\end{array}$ & 50 & $\begin{array}{l}2 \text {-fold } \\
\text { overexpression in } \\
46 \% \text { of tumors }\end{array}$ & qPCR & $\begin{array}{l}\text { High level of TNS2 mRNA expression } \\
\text { correlates with infiltration to blood vessels } \\
\text { and microsatellite instability }\end{array}$ \\
\hline \multicolumn{6}{|l|}{ Tensin-3 } \\
\hline $\begin{array}{l}\text { Martuszewska } \\
\text { et al. [53] }\end{array}$ & $\begin{array}{c}\text { Renal } \\
\text { cancer, } \\
\text { melanoma }\end{array}$ & 260 & $\begin{array}{l}\text { Positive in all } \\
\text { tumors }\end{array}$ & $\begin{array}{l}\mathrm{IHC} \\
\mathrm{qPCR}\end{array}$ & $\begin{array}{l}\text { Positive correlation of TNS3 with survival } \\
\text { and tumor stage }\end{array}$ \\
\hline \multicolumn{6}{|l|}{ Tensin-4 } \\
\hline $\begin{array}{l}\text { Albasri et al. } \\
\text { [63] }\end{array}$ & $\begin{array}{l}\text { Colon } \\
\text { cancer }\end{array}$ & 462 & $\begin{array}{l}\text { Positive in } 90 \% \\
\text { of tumors }\end{array}$ & IHC & $\begin{array}{l}\text { High level of tensin- } 4 \text { expression correlates } \\
\text { with more advanced colorectal cancers, lymph node } \\
\text { metastases, vascular infiltration, distant metastases } \\
\text { and lower total survival rate }\end{array}$ \\
\hline Asiri et al. [19] & $\begin{array}{l}\text { Colon } \\
\text { cancer }\end{array}$ & 84 & $\begin{array}{l}\text { Cytoplasm } \\
\text { reaction }\end{array}$ & IHC & No correlations \\
\hline $\begin{array}{l}\text { Sakashita et } \\
\text { al. [68] }\end{array}$ & $\begin{array}{l}\text { Gastric } \\
\text { cancer }\end{array}$ & 114 & $\begin{array}{l}\text { Higher in } 72 \% \\
\text { of tumors }\end{array}$ & $\begin{array}{l}\mathrm{IHC} \\
\mathrm{qPCR}\end{array}$ & $\begin{array}{l}\text { Significant correlations between increased } \\
\text { expression of TNS4 and a lower degree } \\
\text { of differentiation, infiltration to the serosa, lymph } \\
\text { node metastases, peritoneal carcinomatosis } \\
\text { and cancer-related death. High TNS4 gene } \\
\text { expression links to a shorter total survival time }\end{array}$ \\
\hline $\begin{array}{l}\text { Sawazaki et } \\
\text { al. [69] }\end{array}$ & $\begin{array}{l}\text { Gastric } \\
\text { cancer }\end{array}$ & 130 & High & $\begin{array}{l}\text { IHC, } \\
\text { qPCR }\end{array}$ & $\begin{array}{c}\text { Increased TNS4 expression results in shorter } \\
\text { total survival time }\end{array}$ \\
\hline Qi et al. [13] & $\begin{array}{l}\text { Gastric } \\
\text { cancer }\end{array}$ & 80 & High & $\begin{array}{l}\text { IHC } \\
\text { qPCR }\end{array}$ & $\begin{array}{l}\text { Significant correlation and depth of infiltration, } \\
\text { lymph node metastasis and TNM stage. } \\
\text { Higher tensin- } 4 \text { expression indicates worse } \\
\text { prognosis and shorter survival time }\end{array}$ \\
\hline $\begin{array}{l}\text { Sasaki et al. } \\
\text { [70] }\end{array}$ & $\begin{array}{l}\text { Lung } \\
\text { cancer }\end{array}$ & 89 & $\begin{array}{l}\text { No differences } \\
\text { from normal } \\
\text { tissue }\end{array}$ & qPCR & $\begin{array}{l}\text { Positive correlation of TNS4 expression } \\
\text { with tumor stage }\end{array}$ \\
\hline $\begin{array}{l}\text { Albasri et al. } \\
{[72]}\end{array}$ & $\begin{array}{l}\text { Breast } \\
\text { cancer }\end{array}$ & 1409 & $\begin{array}{l}\text { Positive in } 90 \% \\
\text { of tumors }\end{array}$ & $\mathrm{IHC}$ & $\begin{array}{l}\text { Correlation between high tensin- } 4 \text { expression } \\
\text { and larger tumors }(>1.5 \mathrm{~cm}) \text {, advanced stages, } \\
\text { metastases to nearby lymph nodes, occurrence } \\
\text { of local and surrounding recurrences, higher } \\
\text { Nottingham prognostic index (NPI), histological type } \\
\text { of cancer and distant metastases. Increased tensin-4 } \\
\text { expression is associated with worse prognosis. }\end{array}$ \\
\hline Li et al. [74] & $\begin{array}{l}\text { Prostate } \\
\text { cancer }\end{array}$ & 72 & Low & IHC & $\begin{array}{l}\text { Tensin-4 expression decreased with increased } \\
\text { degree of differentiation. }\end{array}$ \\
\hline $\begin{array}{l}\text { Sjoestroem et } \\
\text { al. [76] }\end{array}$ & Melanoma & 445 & High & $\mathrm{IHC}$ & $\begin{array}{l}\text { Expression of tensin- } 4 \text { increases with melanoma } \\
\text { progression. Higher TNS4 expression is observed } \\
\text { in tumors with a larger diameter and contributes } \\
\text { to shorter total survival time. }\end{array}$ \\
\hline
\end{tabular}




\section{Conflict of interest}

The authors declare no conflict of interest.

\section{References}

1. Charalabopoulos K, Binolis J, Karkabounas S. Adhesion molecules in carcinogenesis. Exp Oncol 2002; 24: 249-57.

2. Opitka MN, Lorenc Z, Starzewska M, Lorenc J, Rajs A. Cell adhesion molecules in terms of carcinogenesis. Pol Przegl Chir 2014; 86: 151-7.

3. Davis S, Lu ML, Lo SH, et al. Presence of an SH2 domain in the actin-binding protein tensin. Science 1991; 252: 712-5.

4. Lo SH. Tensins. Curr Biol 2017; 27: R331-R2.

5. Lo SH. Tensin. Int J Biochem Cell Biol 2004; 36: 31-4.

6. Calderwood DA, Fujioka Y, de Pereda JM, et al. Integrin beta cytoplasmic domain interactions with phosphotyrosine-binding domains: a structural prototype for diversity in integrin signaling. Proc Natl Acad Sci U S A 2003; 100: 2272-7.

7. Blangy A. Tensins are versatile regulators of Rho GTPase signalling and cell adhesion. Biol Cell 2017; 109: 115-26.

8. Forman-Kay JD, Pawson T. Diversity in protein recognition by PTB domains. Curr Opin Struct Biol 1999; 9: 690-5.

9. Hall EH, Balsbaugh JL, Rose KL, Shabanowitz J, Hunt DF, Brautigan DL. Comprehensive analysis of phosphorylation sites in Tensin1 reveals regulation by p38MAPK. Mol Cell Proteomics 2010; 9: 2853-63.

10. Cui Y, Liao YC, Lo SH. Epidermal growth factor modulates tyrosine phosphorylation of a novel tensin family member, tensin3. Mol Cancer Res 2004; 2: 225-32.

11. Zhao Z, Tan SH, Machiyama H, et al. Association between tensin 1 and p130Cas at focal adhesions links actin inward flux to cell migration. Biol Open 2016; 5: 499-506.

12. Chen B, Zhang Y, Li C, Xu P, Gao Y, Xu Y. CNTN-1 promotes docetaxel resistance and epithelial-to-mesenchymal transition via the PI3K/Akt signaling pathway in prostate cancer. Arch Med Sci 2021; 17: 152-65.

13. Qi X, Sun L, Wan J, Xu R, He S, Zhu X. Tensin4 promotes invasion and migration of gastric cancer cells via regulating AKT/GSK-3 $\beta$ /snail signaling pathway. Pathol Res Pract 2020; 216: 153001

14. Georgiadou M, Ivaska J. Tensins: Bridging AMP-Activated Protein Kinase with Integrin Activation. Trends Cell Biol 2017; 27: 703-11.

15. Hiura K, Lim SS, Little SP, Lin S, Sato M. Differentiation dependent expression of tensin and cortactin in chicken osteoclasts. Cell Motil Cytoskeleton 1995; 30: 272-84.

16. Mueller SC, Yeh Y, Chen WT. Tyrosine phosphorylation of membrane proteins mediates cellular invasion by transformed cells. J Cell Biol 1992; 119: 1309-25.

17. Yeung KT, Yang J. Epithelial-mesenchymal transition in tumor metastasis. Mol Oncol 2017; 11: 28-39.

18. Albasri A, Seth R, Jackson D, et al. C-terminal Tensin-like (CTEN) is an oncogene which alters cell motility possibly through repression of $\mathrm{E}$-cadherin in colorectal cancer. J Pathol 2009; 218: 57-65.

19. Asiri A, Toss MS, Raposo TP, et al. Cten promotes Epithelial-Mesenchymal Transition (EMT) in colorectal cancer through stabilisation of Src. Pathol Int 2019; 69: 381-91.

20. Lu X, Gao J, Zhang Y, Zhao T, Cai H, Zhang T. CTEN induces epithelial-mesenchymal transition (EMT) and metastasis in non small cell lung cancer cells. PLoS One 2018 13: e0198823.

21. Hung SY, Shih YP, Chen M, Lo SH. Up-regulated cten by FGF2 contributes to FGF2-mediated cell migration. Mol Carcinog 2014; 53: 787-92.
22. Chen H, Duncan IC, Bozorgchami H, Lo SH. Tensin1 and a previously undocumented family member, tensin2, positively regulate cell migration. Proc Natl Acad Sci U SA 2002; 99: 733-8.

23. Chen H, Ishii A, Wong WK, Chen LB, Lo SH. Molecular characterization of human tensin. Biochem J 2000; 35 : 403-11.

24. Lo SH, Janmey PA, Hartwig JH, Chen LB. Interactions of tensin with actin and identification of its three distinct actin-binding domains. J Cell Biol 1994; 125: 1067-75.

25. Bockholt SM, Burridge K. Cell spreading on extracellular matrix proteins induces tyrosine phosphorylation of tensin. J Biol Chem 1993; 268: 14565-7.

26. Ishida T, Ishida M, Suero J, Takahashi M, Berk BC. Agonist-stimulated cytoskeletal reorganization and signal transduction at focal adhesions in vascular smooth muscle cells require c-Src. J Clin Invest 1999; 103: 789-97.

27. Salgia R, Brunkhorst B, Pisick E, et al. Increased tyrosine phosphorylation of focal adhesion proteins in myeloid cell lines expressing p210BCR/ABL Oncogene 1995; 11: 1149-55.

28. Jiang B, Yamamura S, Nelson PR, Mureebe L, Kent KC. Differential effects of platelet-derived growth factor isotypes on human smooth muscle cell proliferation and migration are mediated by distinct signaling pathways. Surgery 1996; 120: 427-31.

29. Haynie DT. Molecular physiology of the tensin brotherhood of integrin adaptor proteins. Proteins 2014; 82: 1113-27.

30. Hamidi $\mathrm{H}$, Ivaska J. Every step of the way: integrins in cancer progression and metastasis. Nat Rev Cancer 2018; 18: 533-48.

31. Georgiadou M, Lilja J, Jacquemet G, et al. AMPK negatively regulates tensin-dependent integrin activity. J Cell Biol 2017; 216: 1107-21.

32. Schaller MD. Paxillin: a focal adhesion-associated adaptor protein. Oncogene 2001; 20: 6459-72.

33. Hong SY, Shih YP, Li T, Carraway KL, Lo SH. CTEN prolongs signaling by EGFR through reducing its ligand-induced degradation. Cancer Res 2013; 73: 5266-76.

34. Hafizi S, Sernstad E, Swinny JD, Gomez MF, Dahlbäck B. Individual domains of Tensin2 exhibit distinct subcellular localisations and migratory effects. Int J Biochem Cell Biol 2010; 42: 52-61.

35. Hafizi S, Alindri F, Karlsson R, Dahlbäck B. Interaction of $A x l$ receptor tyrosine kinase with C1-TEN, a novel C1 domain-containing protein with homology to tensin. Biochem Biophys Res Commun 2002; 299: 793-800.

36. Cheng LC, Chen YL, Cheng AN, et al. AXL phosphorylates and up-regulates TNS2 and its implications in IRS-1-associated metabolism in cancer cells. J Biomed Sci 2018; 25: 80.

37. Legate KR, Montañez E, Kudlacek O, Fässler R. ILK, PINCH and parvin: the tIPP of integrin signalling. Nat Rev Mol Cell Biol 2006; 7: 20-31.

38. Hafizi S, Ibraimi F, Dahlbäck B. C1-TEN is a negative regulator of the Akt/PKB signal transduction pathway and inhibits cell survival, proliferation, and migration. FASEB J 2005; 19: 971-3.

39. Tripathi BK, Qian X, Mertins P, et al. CDK5 is a major regulator of the tumor suppressor DLC1. J Cell Biol 2014; 207: 627-42.

40. Touaitahuata H, Morel A, Urbach S, Mateos-Langerak J, de Rossi S, Blangy A. Tensin 3 is a new partner of Dock5 that controls osteoclast podosome organization and activity. J Cell Sci 2016; 129: 3449-61.

41. Lo SH. C-terminal tensin-like (CTEN): a promising biomarker and target for cancer. Int J Biochem Cell Biol 2014; 51: 150-4. 
42. Lo SS, Lo SH. Cleavage of cten by caspase-3 during apoptosis. Oncogene 2005; 24: 4311-4.

43. Al-Ghamdi S, Cachat J, Albasri A, et al. C-terminal tensin-like gene functions as an oncogene and promotes cell motility in pancreatic cancer. Pancreas 2013; 42: 135-40.

44. Citri A, Yarden Y. EGF-ERBB signalling: towards the systems level. Nat Rev Mol Cell Biol 2006; 7: 505-16.

45. Lyle CL, Belghasem M, Chitalia VC. c-Cbl: an important regulator and a target in angiogenesis and tumorigenesis. Cells 2019; 8: 498.

46. Carraway KL. E3 ubiquitin ligases in ErbB receptor quantity control. Semin Cell Dev Biol 2010; 21: 936-43.

47. Katz M, Amit I, Citri A, et al. A reciprocal tensin-3-cten switch mediates EGF-driven mammary cell migration. Nat Cell Biol 2007; 9: 961-9.

48. Asiri A, Raposo TP, Alfahed A, Ilyas M. TGF-1-induced cell motility but not cell proliferation is mediated through Cten in colorectal cancer. Int J Exp Pathol 2018; 99: 323-30.

49. Kotepui M, Thawornkuno C, Chavalitshewinkoon-Petmitr P, Punyarit P, Petmitr S. Quantitative real-time RTPCR of ITGA7, SVEP1, TNS1, LPHN3, SEMA3G, KLB and MMP13 mRNA expression in breast cancer. Asian Pac J Cancer Prev 2012; 13: 5879-82.

50. Zhan Y, Liang X, Li L, et al. MicroRNA-548j functions as a metastasis promoter in human breast cancer by targeting Tensin1. Mol Oncol 2016; 10: 838-49.

51. Liao YC, Lo SH. Deleted in liver cancer-1 (DLC-1): a tumor suppressor not just for liver. Int J Biochem Cell Biol 2008; 40: 843-7.

52. Hall EH, Daugherty AE, Choi CK, Horwitz AF, Brautigan $D L$. Tensin1 requires protein phosphatase-1alpha in addition to RhoGAP DLC-1 to control cell polarization, migration, and invasion. J Biol Chem 2009; 284: 34713-22.

53. Martuszewska D, Ljungberg B, Johansson $M$, et al. Ten$\sin 3$ is a negative regulator of cell migration and all four Tensin family members are downregulated in human kidney cancer. PLoS One 2009; 4: e4350.

54. Zhou H, Zhang Y, Wu L, et al. Elevated transgelin/TNS1 expression is a potential biomarker in human colorectal cancer. Oncotarget 2018; 9: 1107-13.

55. Zhang PB, Huang ZL, Xu YH, Huang J, Huang XY. Systematic analysis of gene expression profiles reveals prognostic stratification and underlying mechanisms for muscleinvasive bladder cancer. Cancer Cell Int 2019; 19: 337.

56. Zhu Z, Wen Y, Xuan C, et al. Identifying the key genes and microRNAs in prostate cancer bone metastasis by bioinformatics analysis. FEBS Open Bio 2020; 10: 674-88.

57. Yam JW, Ko FC, Chan CY, et al. Tensin2 variant 3 is associated with aggressive tumor behavior in human hepatocellular carcinoma. Hepatology. 2006; 44: 881-90.

58. Hong SY, Shih YP, Sun P, Hsieh WJ, Lin WC, Lo SH. Down-regulation of tensin2 enhances tumorigenicity and is associated with a variety of cancers. Oncotarget 2016; 7: 38143-53.

59. Shinchi Y, Hieda M, Nishioka Y, et al. SUV42OH2 suppresses breast cancer cell invasion through down regulation of the $\mathrm{SH} 2$ domain-containing focal adhesion protein tensin-3. Exp Cell Res 2015; 334: 90-9.

60. Qian X, Li G, Vass WC, et al. The Tensin-3 protein, including its $\mathrm{SH} 2$ domain, is phosphorylated by $\mathrm{Src}$ and contributes to tumorigenesis and metastasis. Cancer Cell 2009; 16: 246-58.

61. Carter JA, Górecki DC, Mein CA, Ljungberg B, Hafizi S. CpG dinucleotide-specific hypermethylation of the TNS3 gene promoter in human renal cell carcinoma. Epigenetics 2013; 8: 739-47.
62. Chen HY, Lin LT, Wang ML, et al. Musashi-1 enhances glioblastoma cell migration and cytoskeletal dynamics through translational inhibition of tensin3. Sci Rep 2017. 7: 8710 .

63. Albasri A, Al-Ghamdi S, Fadhil W, et al. Cten signals through integrin-linked kinase (ILK) and may promote metastasis in colorectal cancer. Oncogene 2011; 30 2997-3002.

64. Al-Ghamdi S, Albasri A, Cachat J, et al. Cten is targeted by Kras signalling to regulate cell motility in the colon and pancreas. PLoS One 2011; 6: e20919.

65. Thorpe $H$, Akhlaq M, Jackson D, et al. Multiple pathways regulate Cten in colorectal cancer without a Tensin switch. Int J Exp Pathol 2015; 96: 362-9.

66. Liao YC, Chen NT, Shih YP, Dong Y, Lo SH. Up-regulation of C-terminal tensin-like molecule promotes the tumorigenicity of colon cancer through beta-catenin. Cancer Res 2009; 69: 4563-6.

67. Hong SY, Shih YP, Lo A, Lo SH. Identification of subcellular targeting sequences of Cten reveals its role in cell proliferation. Biochim Biophys Acta Mol Cell Res 2019; 1866: 450-8.

68. Sakashita K, Mimori K, Tanaka F, et al. Prognostic relevance of Tensin4 expression in human gastric cancer. Ann Surg Oncol 2008; 15: 2606-13.

69. Sawazaki S, Oshima T, Sakamaki K, et al. Clinical significance of tensin 4 gene expression in patients with gastric cancer. In Vivo 2017; 31: 1065-71.

70. Sasaki H, Moriyama S, Mizuno K, et al. Cten mRNA expression was correlated with tumor progression in lung cancers. Lung Cancer 2003; 40: 151-5.

71. Bennett DT, Reece TB, Foley LS, et al. C-terminal tensin-like protein mediates invasion of human lung cancer cells and is regulated by signal transducer and activator of transcription 3. J Thorac Cardiovasc Surg 2015; 149: 369-75.

72. Albasri A, Aleskandarany M, Benhasouna A, et al. CTEN (C-terminal tensin-like), a novel oncogene overexpressed in invasive breast carcinoma of poor prognosis. Breast Cancer Res Treat 2011; 126: 47-54.

73. Yang K, Wu WM, Chen YC, Lo SH, Liao YC. $\Delta$ Np63 $\alpha$ transcriptionally regulates the expression of CTEN that is associated with prostate cell adhesion. PLoS One 2016; 11: e0147542.

74. Li Y, Mizokami A, Izumi K, et al. CTEN/tensin 4 expression induces sensitivity to paclitaxel in prostate cancer. Prostate 2010; 70: 48-60.

75. Chan LK, Chiu YT, Sze KM, Ng IO. Tensin4 is up-regulated by EGF-induced ERK1/2 activity and promotes cell proliferation and migration in hepatocellular carcinoma. Oncotarget 2015; 6: 20964-76.

76. Sjoestroem C, Khosravi S, Zhang G, Martinka M, Li G. C-terminal tensin-like protein is a novel prognostic marker for primary melanoma patients. PLoS One 2013; 8: e80492.

77. Sasaki H, Yukiue H, Kobayashi Y, Fukai I, Fujii Y. Cten mRNA expression is correlated with tumor progression in thymoma. Tumour Biol 2003; 24: 271-4. 